\title{
Hepcidin Levels and Iron Homeostasis During Early Infancy
}

\author{
Saeed Hammad ${ }^{*}$, Mahmoud El-Gharieb $^{* *}$ and Maher Abdel-Hafez ${ }^{* * *}$ \\ Department of Pediatrics, Batnan Medical Center, Lybia ${ }^{*}$, and \\ Departments of Physiology ${ }^{* *}$ and Pediatric ${ }^{* * *}$ Faculty of Medicine, \\ Tanta University
}

\begin{abstract}
Background: Iron status is usually assessed in children and adults through the measurement of the concentrations of serum ferritin (SF) and serum soluble transferrin receptor (sTfR), which reflect storage iron and cellular iron needs, respectively. However SF and sTfR are difficult to interpret in infants. Hepcidinliver hormone- is a negative regulator of iron absorption and mobilization. Objective: We aimed in this study to characterize changes in hepcidin levels in healthy breast fed infants in correlation to the dynamic change in iron status in this young age. Patients and methods: 106 healthy breast fed infant were included in the study and followed from 4 to $9 \mathrm{mo}$. Iron supplementation was given to infants with iron deficiency (ID) at 6 mo till the age of 9 mo. Blood samples at 4, 6, and 9 months of age were analyzed for hemoglobin ( $\mathrm{Hb}$ ), mean cell volume (MCV), zinc protoporphyrin (ZPP), plasma ferritin, and transferrin receptors (TfR). Urinary hepcidin was measure at 4, 6 and 9 mo. Results: In unsupplemented infants, Hb, $M C V$ and ferritin means decreased, whereas ZPP and sTfR means increased from 4 to 6 mo. Urinary hepcidin levels were decreasing with age between 4 and 6 months. We found significant urinary hepcidin deficiency in ID group at 6 mo. Changes of $\mathrm{Hb}$ levels after iron supplementation were correlated significantly to urinary hepcidin at the age of 6 mo ( $r=-0.756)$, less significantly correlated to sTfR $(r=394)$ and serum ferritin ( $r=32)$. Conclusions: Iron deficiency in healthy full term infants is less common at 4 mo but iron deficiency increased after that. Not all ID infants will manifest by anemia and not all anemic infants are iron deficient. Urinary hepcidin could help to early diagnose infants with true iron deficiency.
\end{abstract}

\section{INTRODUCTION}

Rapid growth and expansion of hemoglobin mass make infants particularly susceptible to iron deficiency. ${ }^{(1)}$ The percentage of low birth weight infants is high in developing countries, and these infants have an even larger weight gain and lower iron stores. Both of these factors have a negative impact on their iron status, placing them at higher risk for iron deficiency at an early age ${ }^{(2)}$. Unlike adult and old children, the main food source for infants is breast milk, which does not contain heme iron. Instead nonheme iron, which is bound to other proteins or low molecular-weight ligands in breast milk, is the form of dietary iron 
for infants. Moreover, iron supplementation, in the form of ferrous sulfate, is the common practice for infants. Hence, the form of dietary iron that infants are exposed to is mainly nonheme.

Studies of human infants indicate that iron deficiency may impair myelination in the central nervous system $^{(3)}$ and that the effects on transmission in the auditory and visual systems persist into childhood ${ }^{(4)}$. A sufficient iron supply in pregnancy and the prevention of iron deficiency in infancy may therefore be of profound importance to the health and development of children.

In the opposite side, However, the benefits and risks of iron supplementation in diverse populations have not been well documented. Iron is an essential nutrient required for infant growth and development, but it is also a potent prooxidant and its effects when given to iron-replete children have not been adequately studied. Iron supplements result in decreased growth ${ }^{(5)}$ in ironreplete infants and may increase the incidence of certain types of infections, particularly gastrointestinal infections $^{(6)}$.

Iron status is usually assessed in children and adults through the measurement of the concentrations of serum ferritin (SF) and serum soluble transferrin receptor (sTfR), which reflect storage iron and cellular iron needs, respectively. Combined with hematologic measurements, these 2 iron indices are believed to provide a good picture of iron status ${ }^{(7)}$.

Indicators of iron deficiency are difficult to interpret in infants, however, because of the effect of coincident changes in physiology and metabolism during growth and development and because of frequent infections ${ }^{(8)}$. The range of SF concentrations is quite wide ${ }^{(9)}$, and normal reference limits are not available. The SF concentration changes markedly during the first year of life ${ }^{(10)}$.

Studies of sTfR in the infants are sparse, but sTfR is believed to reflect erythropoietic activity ${ }^{(11)}$. The value of STfR in the assessment of iron status in the infants has been questioned, however, sTfR are not perfect indicator of iron status because of the weak correlation to other iron indices $^{(2)}$.

Hepcidin, a 25-amino acid peptide produced by hepatocytes, in response to iron loading 12 , is a key iron-regulatory hormone. ${ }^{(13)}$ Hepcidin modulates iron availability by promoting the internalization and degradation of ferroportin ${ }^{(\mathbf{1 4})}$, a key iron transporter and so far the only identified mammalian iron exporter, which is essential for both iron absorption in the duodenum and recycling of iron/iron efflux by macrophages. Hepcidin is a negative regulator of iron absorption and mobilization; high hepcidin levels turn off both duodenal iron absorption and release of iron from macrophages while low hepcidin levels promote iron absorption and heme iron recycling/iron mobilization from macrophages. Thus, hepcidin levels are expected to be high in iron overload states and diminished in iron deficient states. ${ }^{(15)}$

Our aim is to characterize changes in hepcidin levels in healthy breast fed infants in correlation to the 
dynamic changes in iron status in this young age and its response to iron supplementation in comparison to other indices of iron status. We hypothesized that an abnormally low hepcidin levels could individualize infants in need for iron supplementation

\section{SUBJECTS \& METHODS}

\section{Participants}

Healthy, full term infants 4 mo of age were recruited from the Batnan Medical Center, Tobruk, Lybia, after obtaining written informed consent from the parents. Infants were followed during the time interval from 4 to 9 month old. Selection criteria were as follows: 1) gestational age $>37$ wk; 2) birth weight >2500 g; 3) no chronic illness; 4) maternal age $>16 \mathrm{y} ; 5)$ infant exclusively breast-fed at $4 \mathrm{mo}$ (and did not receive $>90 \mathrm{~mL} / \mathrm{d}$ of formula during any period since birth); 6) mother intended to exclusively or nearly exclusively breast-feed until 6 mo (i.e., $>1$ tablespoon $(15 \mathrm{~mL}) / \mathrm{d}$ of foods or fluids other than breast milk, and no iron fortified foods); and 7) mother intended to continue breast-feeding to at least 9 mo. Infants with $\mathrm{Hb}<100$ $\mathrm{g} / \mathrm{L}$ at 4 mo were excluded.

\section{Study Design}

At 6 mo infants were assigned into 2 groups, group A consists of infants showed iron deficiency (ID) (diagnosed as Infants with combination of at least 2 of 3 of the following: $\mathrm{MCV}<70 \mathrm{fL}, \mathrm{ZPP}>80$ $\mu \mathrm{mol} / \mathrm{mol}$ heme, and ferritin $<12$ $\mu \mathrm{g} / \mathrm{L})^{(\mathbf{1 6 )}}$ with or without anemia.

Group B, consists of infants without ID.
Group A were supplemented by iron as iron sulfate $1 \mathrm{mg}$ elemental iron/d, which is the recommended supplemental dose for prophylactic purposes, and the dose was adjusted monthly according to each infant's weight. The supplement was given by the mothers each morning, just before or after breastfeeding and at least 1 hour before or after any other food intake. Compliance with the intervention was monitored by asking the mothers to keep a daily checklist indicating whether the drops were given and by collecting the used iron bottles each month and measuring the amount of fluid remaining. Compliance was defined as taking the study drops for $>75 \%$ of the time during the time intervals (6-9 months).

\section{Biochemical assays.}

Venous blood samples $(5 \mathrm{ml})$ were obtained by venipuncture at 4,6 and 9 mo of age, (sampling was postponed for one week if the infant have acute illness) Part of the sample was collected in an EDTA. ZPP was analyzed (Protofluor Z, Helena Labs, Beaumont, TX).Hematological indices were analyzed by using of a Sysmex SE 9000 Autoanalyzer (Tillqvist). Hb was analyzed using Sysmex Sulfolyser automated hemoglobin reagent and MCV was automatically calculated from erythrocyte

Part of the sample was collected in a lithium heparin tube and, after centrifugation, plasma was stored frozen at $<20^{\circ} \mathrm{C}$ until analyzed for ferritin, TfR and C-reactive protein. Serum ferritin was assessed using an automated chemiluminescence immunoassay analyzer (IMMULITE 
$\left.2000^{\circledR}\right)^{(18)}$ S-TfR was analyzed by ELISA (Ramco, Houston, TX).

Urinary hepcidin measurement at 4, 6 and 9 mo: Urinary creatinine concentrations were measured at first. Hepcidin was detected using rabbit anti-human hepcidin antibody ${ }^{(\mathbf{1 7})}$ with goat anti-rabbit horseradish peroxidase as secondary antibody. Hepcidin quantity in each sample was then normalized using urinary creatinine concentrations and was expressed as nanogram hepcidin per milligram creatinine ${ }^{(\mathbf{1 9})}$.

\section{Statistical analysis}

Data were collected and analyzed using SPSS for windows (version 10). All data were expressed in terms of mean value \pm SD. Comparison of parameters among studied groups were made using student $\mathrm{t}$ test. Results were considered significant at $P$ value $<0.05$. Correlation of variables were done using Pearson correlation test.

\section{RESULTS}

At 4 months old 130 infants were included in the study. Remaining in the study were 115 infants at 6 months and 106 at 9 months. Only infants remaining in the study at 9 months were included in the statistical analyses to allow direct comparison with the same infants.

Characteristics of the subjects at 4 and 6 months of age are shown in

Table 1.

There were no significant differences between sexes at 4 months. Iron deficiencies (group A) at age of 6 months were more common among boys compared to girls $(\mathrm{P}<0.001)$. ID infants showed low weight at birth and rapid weight gain compared to infants without ID (group B) (Table I).

Table I: Participant characteristics

\begin{tabular}{|l|l|l|l|c|}
\hline \multirow{2}{*}{ Patient information } & \multirow{2}{*}{$\begin{array}{c}\text { At 4 months } \\
(\mathbf{n = 1 0 6 )}\end{array}$} & \multicolumn{2}{|c|}{ Infants at 6 months } & \multirow{2}{*}{ Proup A } \\
\cline { 3 - 4 } & & $\begin{array}{c}\text { Group B } \\
\text { N=56 }\end{array}$ & P1 \\
\hline Boys n (\%) & $54(51 \%)$ & $34(60.7 \%)$ & $20(40 \%)$ & $<0.001$ \\
Girls n (\%) & $52(49 \%)$ & $22(39.3 \%)$ & $30(60 \%)$ & $<0.001$ \\
Birth weight(Kg) & $3.4 \pm 0.6$ & $3.2 \pm 0.5$ & $3.5 \pm 0.4$ & $<0.001$ \\
Weight gain (0-9 months) & & $5.3 \pm 0.9$ & $4.8 \pm 0.9$ & $<0.001$ \\
\hline
\end{tabular}

P1: comparing group A Vs group B

Table I: shows that boys compared with girls had statistically significant incidence of ID (group A). Infants with ID at 6 month were of low birth weight and showed significant weight gain compared to infants without ID

In unsupplemented infants, $\mathrm{Hb}$, MCV and ferritin means decreased, whereas ZPP and sTfR means increased from 4 to 6 months. This was paralleled by increasing SD, possibly suggesting an increasing proportion of iron-deficient infants. The only exception was $\mathrm{Hb}$, for which the SD did not increase. This may suggest that the decrease in $\mathrm{Hb}$ from 4 to 6 months was physiologic and that the proportion of infants who developed anemia between 4 and 6 months of age was low despite the increasing ID with age. 
Table II: Iron status in infants at 4 and 6 months of age.

\begin{tabular}{|l|l|l|l|l|l|l|}
\hline & $\begin{array}{c}\text { At 4 } \\
\text { months } \\
\text { N=106 }\end{array}$ & $\begin{array}{c}\text { Group A } \\
\text { (n=56) }\end{array}$ & $\begin{array}{c}\text { Group B } \\
\text { (50) }\end{array}$ & \multirow{2}{*}{ P1 } & \multirow{2}{*}{ P2 } & P3 \\
& & & & & \\
\hline Hb $(\mathrm{g} / \mathrm{L})$ & $119.2(9)$ & $\mathbf{1 0 3 . 6 ( 8 )}$ & $\mathbf{1 1 3 . 5}(7)$ & $<0.001$ & $<\mathbf{0 . 0 0 1}$ & $<\mathbf{0 . 0 0 1}$ \\
MCV $(\mathrm{fL})$ & $\mathbf{7 7 . 6 ( 3 . 0 )}$ & $\mathbf{7 2 . 8 ( 3 . 8 )}$ & $\mathbf{7 6 ( 3 . 6 )}$ & $<0.005$ & $<\mathbf{0 . 0 0 5}$ & $<\mathbf{0 . 0 5}$ \\
ZPP $(\mu \mathrm{mol} / \mathrm{mol}$ heme) & $\mathbf{4 7 ( 1 . 3 )}$ & $\mathbf{5 5}(1.6)$ & $\mathbf{5 0 ( 1 . 5 )}$ & $<0.001$ & $<\mathbf{0 . 0 0 1}$ & $<\mathbf{0 . 0 5}$ \\
Ferritin $(\mu \mathrm{g} / \mathrm{L})$ & $\mathbf{8 5}(\mathbf{2 . 5})$ & $\mathbf{4 5}(\mathbf{2 . 8})$ & $\mathbf{6 8}(\mathbf{2 . 6})$ & $<0.001$ & $<\mathbf{0 . 0 0 1}$ & $<\mathbf{0 . 0 0 1}$ \\
sTfR $(\mathrm{mg} / \mathrm{L})$ & $\mathbf{7 . 6 ( 1 . 6 )}$ & $\mathbf{9 . 4 ( 2 . 7 )}$ & $\mathbf{7 . 8 ( 2 . 5 )}$ & $<0.05$ & $<\mathbf{0 . 0 5}$ & $>\mathbf{0 . 0 5}$ \\
\hline
\end{tabular}

P1 Group A Vs Group B

$P 2$ Infants at 4 month Vs group A

$P 3$ Infants at 4 months Vs group $B$

Mean (standard deviation) for $\mathrm{Hb}, \mathrm{MCV}$, and TfR. Geometric mean (standard deviation) for ferritin and ZPP. Note that, whereas the arithmetic standard deviation is added (subtracted) to the mean, the geometric standard deviation is multiplied (divided) with the geometric mean.

Table II: shows that the mean $\mathrm{Hb}, \mathrm{MCV}$ and Ferritin levels were significantly high in infants at 4 months compared to both groups of infants at 6 months with significant lower levels in group A compared to group B. ZPP and sTfR levels were significantly lower in infants at 4 month compared to both groups at 6 months and in group B compared to group A.

Iron deficiency and IDA at the age of 4 mo was absent in our healthy well selected breast fed infants. About $53 \%$ of infants $(\mathrm{n}=56)$ at 6 months showed iron deficiency diagnosed by abnormal 2 of the 3 parameters (MCV, FT, and ZPP). Anemia was manifested in 40 (about $37.7 \%$ ) of our infants population at the age of $6 \mathrm{mo}$. Anemia was diagnosed by $\mathrm{Hb}$ levels less than $105 \mathrm{~g} / \mathrm{L}$ (20). Anemia without ID was detected in 5 infants and ID without anemia was diagnosed in 21 infants.

Urinary hepcidin levels were decreasing with age between 4 and 6 months (Tab III). With more significant decrease in ID group. Whether this decrease in Hepcidin is related to iron homeostasis or not was investigated by estimating the response of hepcidin to iron supplementation. "true" iron deficient infants will response to iron supplementation with elevation in $\mathrm{Hb}$ levels. So iron supplementation was given to the ID group from 6 to 9 months and the change in $\mathrm{Hb}$ levels was correlated to different parameters of iron status. 
Table III: Comparison of urinary hepcidin levels in ng per mg creatinine between infants at 4 and 6 months.

\begin{tabular}{|l|l|l|l|}
\hline \multirow{2}{*}{ Urinary hepcidin level } & \multicolumn{1}{|c|}{$\begin{array}{c}\text { At 4 months } \\
(\mathbf{n = 1 0 6 )}\end{array}$} & \multicolumn{1}{c|}{$\begin{array}{c}\text { At 6 months } \\
\text { Group A } \\
\mathbf{N}=\mathbf{5 6}\end{array}$} & $\begin{array}{c}\text { Group B } \\
\mathbf{n = 5 0}\end{array}$ \\
\hline Range & \multicolumn{1}{|c|}{} & $20-60$ & $49-90$ \\
Mean & 80.122 & 38.5 & 67.85 \\
SD \pm & 21.2 & 11.5 & 11.4 \\
P1(A vs B) & $\mathbf{0 . 0 0 1}$ & & \\
P2( at 4 mo Vs A) & $\mathbf{< . 0 0 1}$ & & \\
P3( at 4 mo Vs B) & $\mathbf{< , 0 5}$ & & \\
\hline
\end{tabular}

Table III shows that the mean urinary hepcidin levels were significantly lower in infants with ID (group A) at age of 6 months compared with infants without ID (group B) $(\mathrm{P} 1<0.001)$ and infants at 4 months $(\mathrm{P} 2<0.001)$. Mean urinary hepcidin levels in infants without ID at 6 mo were significantly lower compared to infants at 4 months (P3<0.05).

$\mathrm{Hb}$ response to iron supplementation of more than $5 \mathrm{~g} / \mathrm{L}$ was found in $42(75 \%)$ of ID infants. Mean $\mathrm{Hb}$ increased after iron supplementation by $9.6 \mathrm{~g} / \mathrm{L}$ while mean $\mathrm{Hb}$ levels decreased in the unsuplemented group by $4.5 \mathrm{~g} / \mathrm{L}$. $\mathrm{MCV}$, ferritin and urinary hepcidin were significantly increased while sTfR and ZPP were significantly decreased after iron supplementation compared to unsupplemented group (Tab. IV).

Table IV: Iron status in infants at age of 9 months

\begin{tabular}{|l|c|c|c|}
\hline & $\begin{array}{c}\text { Group A } \\
(\mathbf{n = 5 6})\end{array}$ & $\begin{array}{c}\text { Group B } \\
(\mathbf{n = 5 0})\end{array}$ & P value \\
\hline Hb $(\mathrm{g} / \mathrm{L})$ & $\mathbf{1 1 3 ( 8 )}$ & $\mathbf{1 0 9}(7)$ & $<\mathbf{0 . 0 0 1}$ \\
MCV $(\mathrm{fL})$ & $\mathbf{7 7 . 5 ( 4 . 2 )}$ & $\mathbf{7 2}(\mathbf{2 . 7 )}$ & $<\mathbf{0 . 0 0 1}$ \\
ZPP $(\mu \mathrm{mol} / \mathrm{mol}$ heme) & $\mathbf{4 6 ( 2 )}$ & $\mathbf{5 8}(1.6)$ & $<\mathbf{0 . 0 0 1}$ \\
Ferritin $(\mu \mathrm{g} / \mathrm{L})$ & $\mathbf{6 7 ( 2 . 7 )}$ & $\mathbf{4 5}(\mathbf{2 . 5})$ & $<\mathbf{0 . 0 0 1}$ \\
sTfR $(\mathrm{mg} / \mathrm{L})$ & $\mathbf{6 . 1 ( 2 . 1 )}$ & $\mathbf{8 . 5}(\mathbf{2 . 2})$ & $<\mathbf{0 . 0 0 1}$ \\
hepcidin $*$ & $\mathbf{1 0 2 ( 1 5 )}$ & $\mathbf{5 5 ( 1 2 )}$ & $<\mathbf{0 . 0 0 1}$ \\
\hline
\end{tabular}

* Urinary hepcidin levels in $\mathrm{ng}$ per mg creatinine

Table IV: Shows significant elevation in $\mathrm{Hb}, \mathrm{MCV}$, ferritin and urinary hepcidin levels whereas STfR and ZPP were decreased in ID group (group A) after iron supplementation compared to non supplemented infants.

Mean (standard deviation) for $\mathrm{Hb}, \mathrm{MCV}$, and TfR. Geometric mean (standard deviation) for ferritin and
ZPP. Note that, whereas the arithmetic standard deviation is added (subtracted) to the mean, the geometric standard deviation is multiplied (divided) with the geometric.

Changes of $\mathrm{Hb}$ levels after iron supplementation is considered the gold stander for the diagnosis of ID in infants, these changes were correlated 
significantly to urinary hepcidin at the age of 6 mo ( $\mathrm{r}=-0.876)$ (Fig 1), less significantly correlated to sTfR $(\mathrm{r}=476)($ Fig 2$)$ and serum ferritin $(\mathrm{r}=$ -354) (Fig 3).

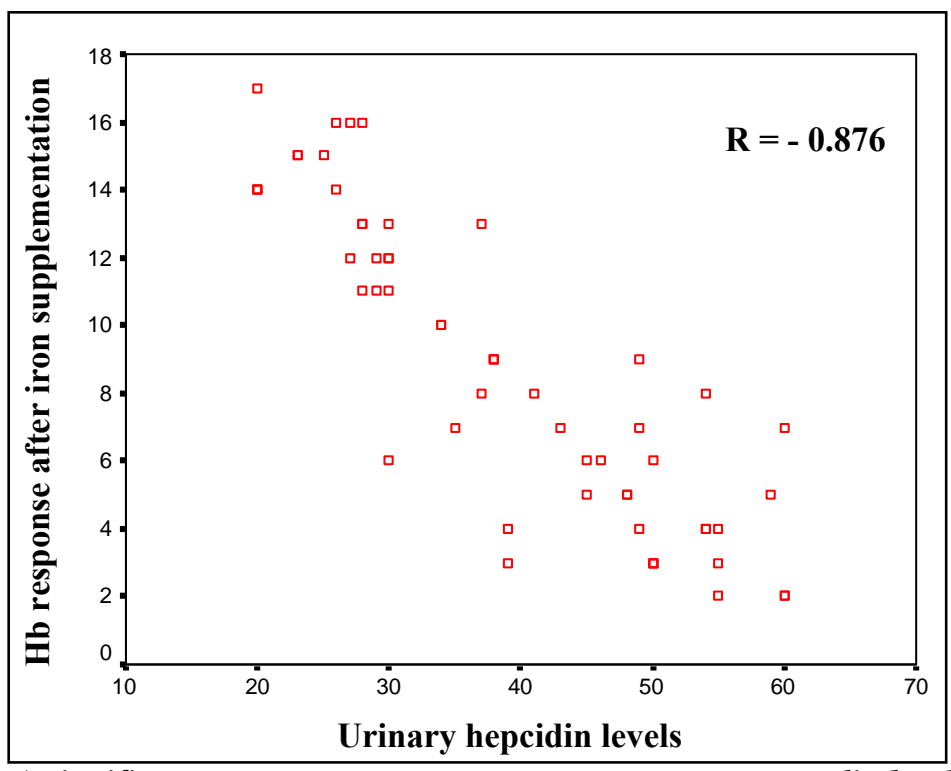

Fig.1: A significant negatıve correıtıons petween urınary nepcıdin levels in infants with ID at 6 mo and the increase in Hb levels after iron supplementation.

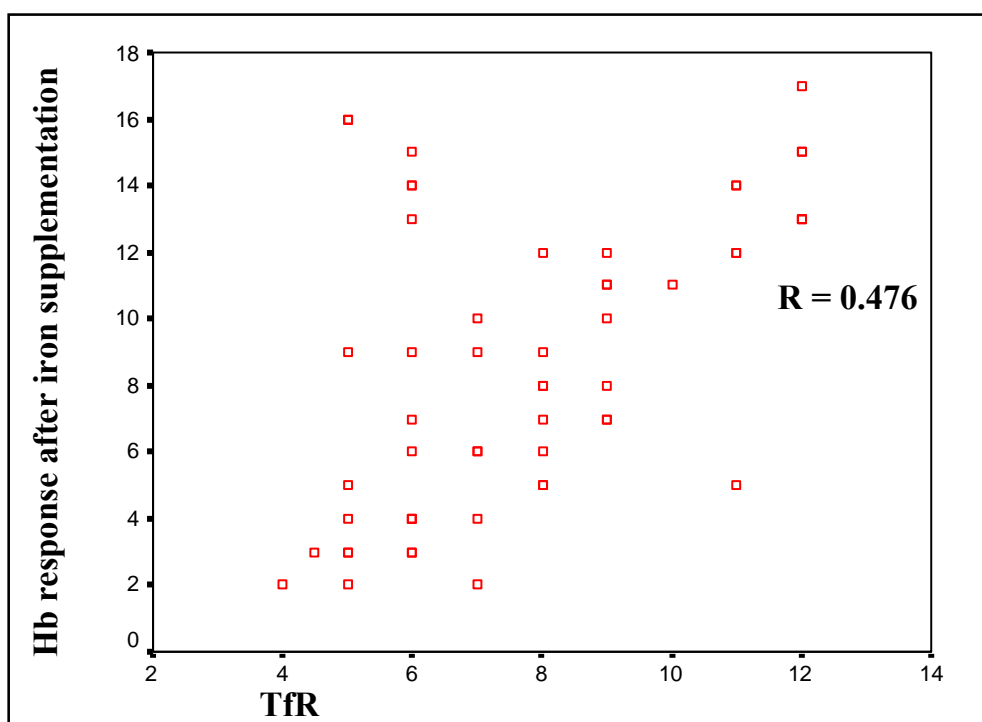

Fig.2 positive Correlation between sTfR levels in infants with ID at age of 6 mo and the increase in $\mathrm{Hb}$ levels after iron supplementation. 


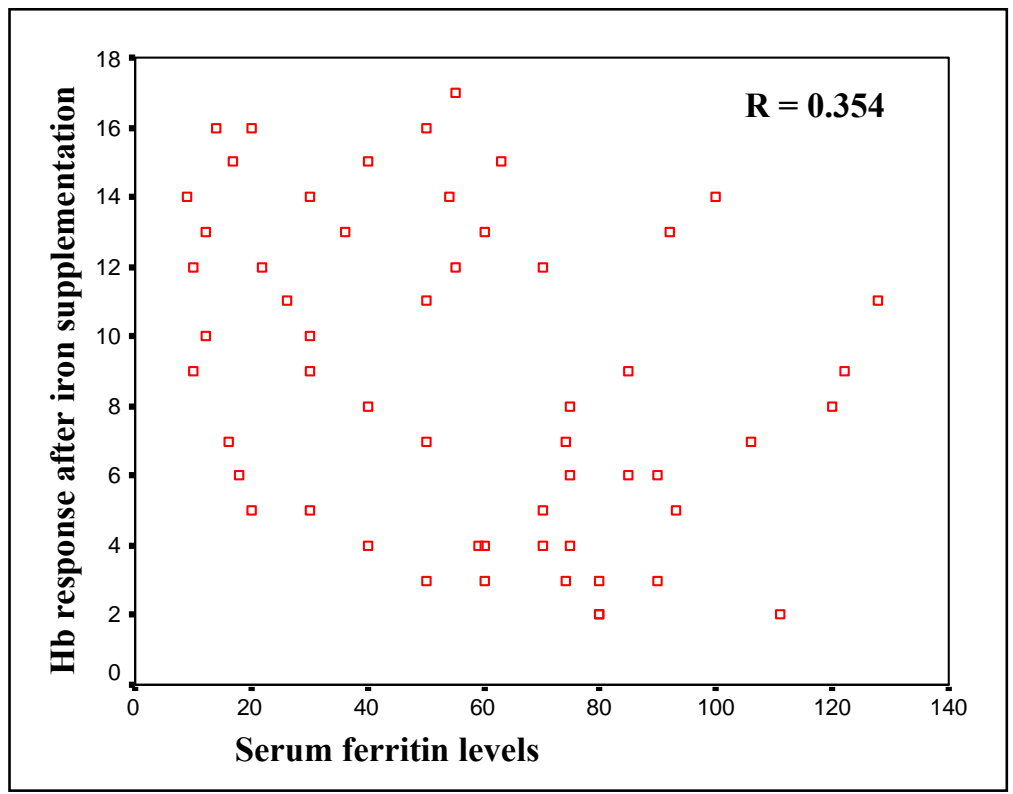

Fig.3: Correlations between serum ferritin levels in infants with ID at age of 6 months and the increase in $\mathrm{Hb}$ levels after iron supplementation.

\section{DISCUSSION}

Most health authorities recommend exclusive breastfeeding for 4-6 mo, a practice thought to prevent development of iron deficiency anemia in term, healthy infants $^{(21)}$. However, if infants are exclusively breast-fed beyond that age, they are at increasing risk of developing iron deficiency anemia. To prevent this, iron supplements (in the form of liquid drops) are often recommended for breast-fed infants after 6 months of age if they do not consume adequate amounts of ironrich complementary foods ${ }^{(22)}$.

Our results confirmed this practice as iron deficiency anemia was not detected in infants at the age of 4 mo in our healthy term, breast fed infants. Anemia was found in 40 $(37.7 \%)$ of unsupplemented infants at 6 mo. Criteria of IDA was met in 35 of them $(87.5 \%)$. ID was more common in Lybian infants compared to Europeans and nearly the same incidence like in Chile. Only 24\% of anemic infants met the criterion for iron deficiency in Europian study ${ }^{(\mathbf{2 3})}$, whereas $85 \%$ of those infants in Chile did so $^{(24)}$. This difference may be explained by the socioeconomic factors which would act through physiologic factors, such as a poorer diet for infant, mother, or both or more childbearing and hence poorer maternal nutrition.

Iron supplementation significantly increased $\mathrm{Hb}$ levels at 9 
month while unsupplemented infants without ID (group B) showed a decrease in mean $\mathrm{Hb}$ levels of $4.5 \mathrm{~g} / \mathrm{L}$.

Estimates of iron requirements in infancy and recommendations regarding the quantity of iron to be used to fortify infant foods are often derived from absorption data $^{(25)}$. In healthy adults, absorption of iron increases in states of iron depletion, but it is not known if the same regulating mechanism functions during infancy, a period characterized by dramatic changes in the size of iron stores and the rate of erythropoiesis. We found different hemoglobin responses to iron supplementation after 6 months of age $-25 \%$ of infants showed $\mathrm{Hb}$ response less than $5 \mathrm{~g} / \mathrm{L}$ - suggesting other deficiencies rather than iron.

Girls have iron index values that are consistent with better iron status than those in boys. That finding was also reported previously ${ }^{(\mathbf{2 4 , 2 5})}$. This sex difference may be -in part- explained by more weight gain in the first year of life in boys compared to girls.

Hepcidin is a key regulator of iron homeostasis and is, now emerging as a fundamental diagnostic parameter of iron overload.

Hepcidin was significantly high in our infants at 4 months. And decreased significantly at the age of 6 months particularly in ID group. Domellöf et-al found insignificant difference in iron absorption between iron supplemented and unsupplemented infants at 4- 6 months. ${ }^{(27)}$ Hepcidin may downregulates intestinal iron absorption in these presumably iron-sufficient infants regardless of dietary iron intake. However, recent data from animal studies suggest that the expression of iron transporter (divalent metal transporter1 (DMT1) and ferroportin1 (FPN1)- is not increased by Iron deficiency during early infancy but is increased in late infancy(28), which would support our findings.

Tiker et al revealed no significant correlations between serum prohepcidin level and serum iron, serum ferritin, or transferrin in the preterm or term newborns and that healthy preterm and term newborns have high pro-hepcidin levels.

On the other hand, Orhon et al. ${ }^{(29)}$ indicated that serum pro-hepcidin levels in anaemic infants were similar to those of healthy ones. Regarding with this unexpected finding, we suggest that pro-hepcidin levels might not reflect the actual hepcidin levels, and this prohormone might not be a useful biomarker for clinical purposes $^{(\mathbf{3 0})}$.

Urinary hepcidin levels were significantly correlated with the change of $\mathrm{Hb}$ levels in response to iron supplementation. This correlation was less significant with ferritin and sTfR. Which may reflect that urinary hepcidin may be better predictor of "true iron deficiency" than other parameters.

Urinary hepcidin levels were well correlated to serum hepcidin levels. Ganz et-al ${ }^{(31)}$ provided validation of a novel immunoassay for human serum hepcidin The availability of this assay opens the way to early diagnosis of infants with IDA.

In conclusion: Iron deficiency in healthy full term infants is less common at 4 mo but iron deficiency increased after that. Not all ID infants 
will manifest anemia and not all anemic infants are iron deficient. Urinary hepcidin could help in early diagnosis of infants with true iron deficiency.

\section{REFERENCES}

1. Michaelsen KF, Milman $\mathbf{N}$, Samuelson G. A longitudinal study of iron status in healthy Danish infants: effects of early iron status, growth velocity and dietary factors. Acta Paediatr 1995;84:1035- 44.

2. Kuiper-Kramer EP, Baerts W, Bakker R, van Eyck J, van Raan J, van Eijk HG. Evaluation of the iron status of the newborn by soluble transferring receptors in serum. Clin Chem Lab Med 1998;36:1721.

3. Roncagliolo M, Garrido M, Walter T, Peirano P, Lozoff B. Evidence of altered central nervous system development in infants with iron deficiency anemia at 6 mo: delayed maturation of auditory brainstem responses. Am J Clin Nutr 1998;68:683-90.

4. Algarin C, Peirano P, Garrido M, Pizarro F, Lozoff B. Iron deficiency anemia in infancy: long-lasting effects on auditory and visual system functioning. Pediatr Res 2003;53:217-23.

5. Idjradinata, P., Watkins, W. \& Pollitt, E. Adverse effect of iron supplementation on weight gain of iron-replete young children. Lancet 1994; 343:1252-1254.

6. K G. Dewey, M Domello“ f, R J. Cohen, L L Rivera, O Hernell and B L Nnerdal. Iron Supplementation Affects Growth and Morbidity of Breast-Fed Infants: Results of a Randomized Trial in Sweden and Honduras 1 J. Nutr. 132: 3249-3255, 2002.

7. Cook JD. Diagnosis and management of iron-deficiency anaemia. Best Pract Res Clin Haematol 2005;18:319 -32.

8. Aggett PJ, Agostoni C, Axelsson I, et al. Iron metabolism and requirements in early childhood: do we know enough? A commentary by the ESPGHAN Committee on Nutrition. J Pediatr Gastroenterol Nutr 2002; 34:337- 45.

9. Fleming RE. Cord serum ferritin levels, fetal iron status, and neurodevelopmental outcomes: correlations and confounding variables. $\mathrm{J}$ Pediatr 2002;140:145-8.

10. Siimes MA, Addiego JE Jr, Dallman PR. Ferritin in serum: diagnosis of iron deficiency and iron overload in infants and children. Blood 1974; 43:581-90.

11. Choi JW,KimCS, Pai SH. Erythropoietic activity and soluble transferrin receptor level in neonates and maternal blood. Acta Paediatr 2000;89: 675-9.

12. Park CH, Valore EV, Waring AJ and Ganz T. Hepcidin, a urinary antimicrobial peptide synthesized in the liver. J Biol Chem. 2001; 276: 7806-7810.

13. Ganz T. Hepcidin in iron metabolism. Curr Opin Hematol. 2004; 11: 251-254.

14. Nemeth E, Tuttle MS, Powelson J, Vaughn MB, Donovan A, Ward DM, et al. Hepcidin 
regulates cellular iron efflux by binding to ferroportin and inducing its internalization. Science 2004;306:2090-3.7-

15. Pigeon C, Ilyin G, Courselaud B, Leroyer P, Turlin B, Brissot $\mathbf{P}$, et al. A new mouse liverspecific gene, encoding a protein homologous to human antimicrobial peptide hepcidin, is overexpressed during iron overload. J Biol Chem 2001;276:7811-9.

16. Domello“ FM, Cohen RJ, Dewey KG, Hernell O, Rivera LL, Lönnerdal B. Iron supplementation of breast-fed Honduran and Swedish infants from 4 to 9 months of age. $J$ Pediatr. 2001;138:679-687.

17. Nemeth $E$ and Ganz $T$. Regulation of iron metabolism by hepcidin. Annu Rev Nutr 2006; 26:323-42.

18. Desmet VJ, Gerber M, Hoofnagle JH, Manns $M$ and Scheuer PJ. Classification of chronic hepatitis: diagnosis, grading and staging. Hepatology 1994; 19:1513-20.

19. Nemeth E, Rivera S, Gabayan $\mathbf{V}$, et al. IL-6 mediates hypoferremia of inflammation by inducing the synthesis of the iron regulatory hormone hepcidin. J Clin Invest. 2004;113:12711276.

20. M Domello, KG. Dewey, BL Nnerdal, RJ Cohen and $O$ Hernell: The Diagnostic Criteria for Iron Deficiency in Infants Should Be Reevaluated: J. Nutr. 132: 3680-3686, 2002.

21. American Academy of Pediatrics. Work Group on
Breastfeeding. Breastfeeding and the use of human milk. Pediatrics 1997; 100: 1035-9.

22. Centers for Disease Control and Prevention. Recommendations to prevent and control iron deficiency in the United States. MMWR Morb Mortal Wkly Rep 1998;47:1-29.

23. Male C, Persson LA, Freeman $\mathbf{V}$, et al. Prevalence of iron deficiency in 12-mo-old infants from 11 European areas and influence of dietary factors on iron status (Euro-Growth Study). Acta Paediatr 2001;90: 492-8.

24. B Lozoff, $N$ Kaciroti, and $T$ Walter. Iron deficiency in infancy: applying a physiologic framework for prediction $A m J$ Clin Nutr 2006;84:1412-21.

25. Committee on Nutrition, American Academy of Pediatrics. Iron fortification of infant formulas. Pediatrics 1999; 104:119-23.

26. M Domello, BL Nnerdal, KG Dewey, RJ Cohen, LL Rivera and $O$ Hernell. Sex Differences in Iron Status During Infancy Pediatrics 2002; 110:545-552.

27. M Domellöf, B Lönnerdal, SA Abrams, and $O$ Hernell. Iron absorption in breast-fed infants: effects of age, iron status, iron supplements, and complementary foods Am J Clin Nutr 2002; 76:198-204.

28. Leong, Weng-In, CL Bowlus, Jonas $T$, and BL Nnerdal. DMT1 and FPN1 expression during infancy: developmental regulation of iron absorption. Am J Physiol Gastrointest Liver 
Physiol 285: G1153-G1161, 2003.

29. FS Orhon, B. Ulukol, A. Hanoluk, N AkarInt. Serum pro-hepcidin levels in infants with iron deficiency anaemia Jnl. Lab. Hem. 2008, 30, 546-547.

30. Roe MA, Spinks C, Heath AL, et al. Serum prohepcidin concentration: no association with iron absorption in healthy men; and no relationship with iron status in men carrying HFE mutations, hereditary haemochromatosis patients undergoing phlebotomy treatment, or pregnant women. $\mathrm{Br}$ J Nutr. 2007; 97:544-549.

31. T Ganz, G Olbina, D Girelli, E Nemeth $^{2}$, and $M$ Westerman: Immunoassay for human serum hepcidin. Blood, 15 November 2008, Vol. 112, No. 10, pp. 42924297.

\title{
مستوى الهبسيدين و الثبات الاخلى للحديد بالام في الأطفال الرضع
}

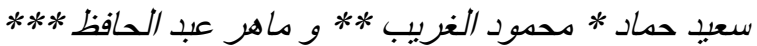

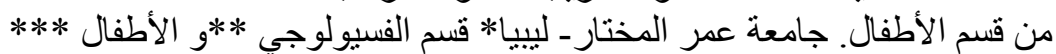 \\ كلية طب طنطا - مصر - مصن الفر
}

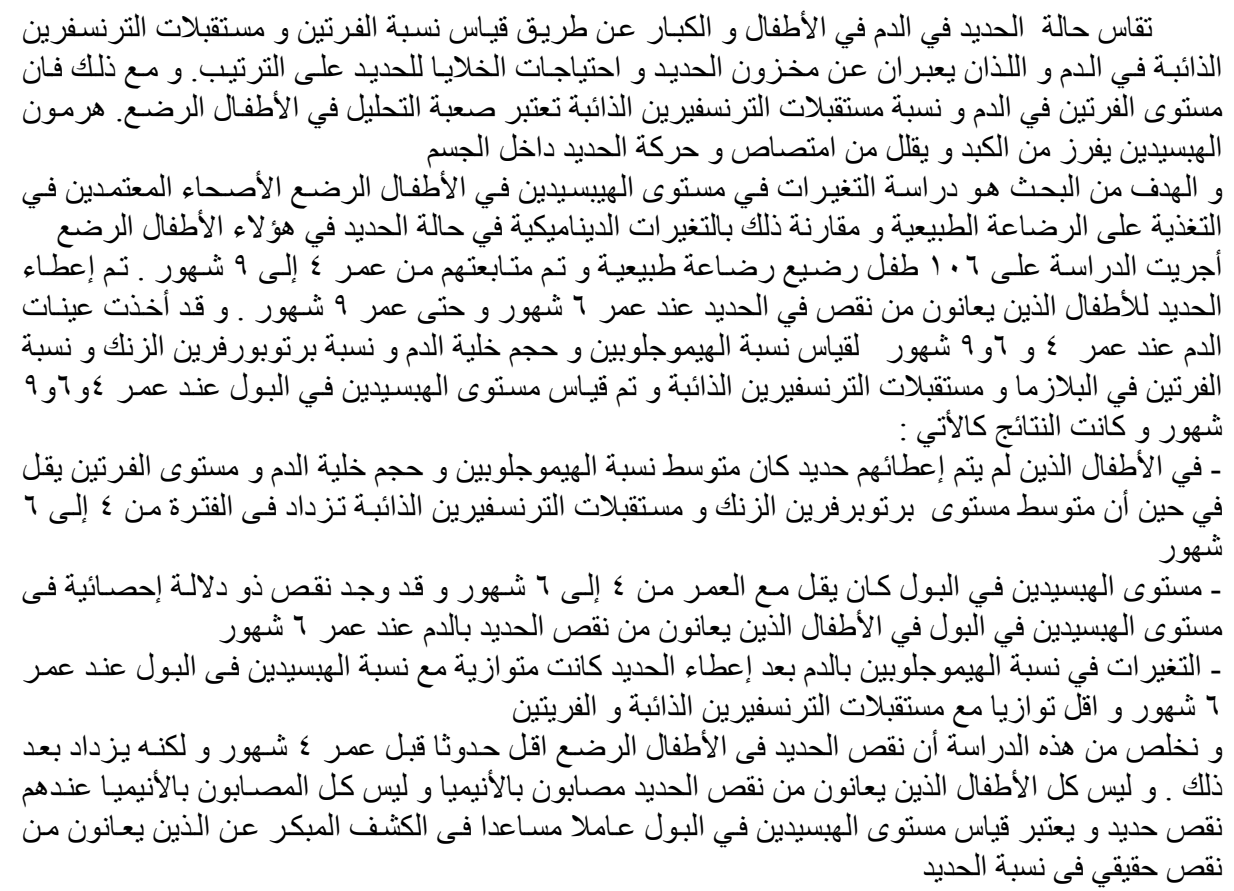

